In Crescendo. Institucional. 2017; 8(1): 61-66

Fecha de recepción: 20 de marzo de 2017

Fecha de aceptación: 30 de marzo de 2017

\title{
ApreHENSIÓn CONCEPTUAL DE LA PEDAGOGÍA: \\ UN ACERCAMIENTO REFLEXIVO A SU NATURALEZA
}

\section{Conceptual Approach to Pedagogy: A Reflexive Approach to his Nature}

\author{
Erika Paola Motta Totena*
}

\section{RESUMEN}

E presente documento es el resultado de un acercamiento crítico y reflexivo al concepto de pedagogía y a la resonancia pragmática que tiene este en los constructos ideológicos y culturales de los agentes educativos, en este sentido se pretende esclarecer desde la complejidad educativa el germen de disparidad terminológica que va en aumento en cuanto a la ambigüedad, saturación y extra polarización del universo pedagógico.

Palabras clave: Educación, epistemología, pedagogía.

\begin{abstract}
This document is the result of a critical and reflective approach to the concept of pragmatic pedagogy and the resonance it has in the ideological and cultural constructs of educators in this regard is to clarify from the educational complex germ terminological disparity is increasing in terms of ambiguity, extra saturation and polarization of the pedagogical University.
\end{abstract}

\footnotetext{
* Colombiana, Licenciada en Lengua Castellana (Universidad del Tolima), Grado de Honor Máximo, Especialista en Pedagogía (Universidad del Tolima), Magíster en Educación (Universidad del Tolima). Estudiante de Doctorado en Educación con especialidad en Mediación Pedagógica (Universidad de la Salle, Costa Rica). Tutora del Programa Todos a Aprender del Ministerio de Educación Nacional de Colombia. Docente de la Secretaría de Educación de Ibagué- Tolima. Docente-catedrática de la Universidad del Tolima, en los programas de Pregrado (IDEAD): Administración Turística y Hotelera, Administración Financiera, Tecnología en Regencia de Farmacia y de Posgrado: Especialización en Pedagogía. Correo electrónico: paomotta02@hotmail.com.
} 
Keywords: Education, epistemology, pedagogy.

\section{INTRODUCCIÓN}

Sin duda alguna, uno de los horizontes a los que han ido aspirando las Instituciones Educativas y por ende los docentes, es el de examinar con frecuencia sus procesos formativos en el marco de la sociedad, a toda vez que el aula termine convirtiéndose en una especie de "laboratorio"; en el cual se aborden y exploren ejes problemáticos como la inclusión y repercusión de las nuevas tecnologías de la información, la constitución de nuevos saberes virtuales, el apogeo de nuevas tribus urbanas, el acercamiento a nuevos estilos de enseñanza/aprendizaje, y la riqueza didáctica mediante el trabajo con comunidades con necesidades educativas especiales - NEE, de tal manera que la Escuela se convierta paulatinamente en un microcosmos de lo que sucede en la cotidianidad.

En esta dirección, el hecho que los docentes se comprometan por buena parte de estos aspectos inmediatos y por qué no, por los que pueden ocurrir a posteriori mientras se orienta una clase, es un ejercicio valioso que ha sido aprovechado por muchos para portar el emblema de la calidad educativa. Desde una mirada introspectiva (subjetiva) sobre los propósitos que debe perseguir la educación como soporte de la sociedad, se encuentra justo el de garantizar que no sólo el estudiante sino la misma comunidad se vincule con las exigencias actuales del hombre a las que debe responder la escuela. El problema ha sido que les han delegado únicamente a los educadores la tarea de involucrarse en las dimensiones estéticas, económicas, afectivas, psicológicas y culturales; cuando es en realidad una tarea de varios agentes sociales (familia, pares académicos, amigos, medios de comunicación), pero que por los múltiples baches estructurales de nuestro medio, es más cómodo legalmente asignarles esa obligación a los maestros.

\section{Mediaciones desde el docente}

Con lo anterior es posible que se piense, que el papel del maestro llega a los confines del mártir, porque media intereses sociales, sacrifica sus convicciones y sería siempre a quien se le atribuyen los traspiés. Sin embargo, la intención es más bien mostrar cómo lo que es en cierta medida un compromiso del docente (ser uno de los agentes dinámicos de la sociedad), es un deber decretado por el que todos reclaman y que a su vez todos deben asumir. Este panorama pone de frente varias preocupaciones y mediaciones, entre las que se destacan las interrogantes en torno a cuál es el concepto de la educación y de la pedagogía que se ha venido gestando a lo largo del devenir de la historia humana. Y más enfáticamente, la impresión que la educación se ha ido quedando y resignificando en concordancia con los referentes pragmáticos de la sociedad de consumo y producción.

Dar respuesta a este cuestionamiento representa reconocer que la gran mayoría de problemáticas ontológicas y epistemológicas de la educación, tienen de base un deseo por indagar la cuestión terminológica, evadida por unos y acartonada por otros. Al respecto, la última de las inquietudes en donde se intenta observar hasta qué punto es válido inclinarse con más vehemencia por los aspectos pragmáticos, admite un posible quiebre con los referentes teóricos que también le competen pensar a la educación. Aspectos 
como la pedagogía -que todo maestro dice tener para guiar su labor educativa- quedan anclados al cliché de "la práctica hace al maestro", sin la menor posibilidad de volver inteligible -por decirlo de alguna manera- la experiencia pedagógica.

Por lo cual, el sentido que adquiere la naturaleza de la pedagogía emana en sí mismo cierta complejidad a la hora de delimitarla conceptualmente; no obstante la disertación sobre este concepto podría contribuir en el esclarecimiento de lo teórico y el pragmatismo. La idea de reflexionar sobre la pedagogía es un acto espinoso, puesto que existen múltiples definiciones sobre la misma, por ejemplo algunos la denominan ciencia, otros disciplina, también la han designado como proceso reflexivo, incluso la han denominado destreza, y es evidente que hasta el momento no hay claridad, por eso hay quienes hablan de la pedagogía conceptual, la pedagogía de la escuela nueva, del constructivismo y hasta de que cada maestro posee una propia.

En esta línea temática, es notorio que el mismo trasegar histórico e ideológico del concepto de pedagogía ha dado lugar a la disparidad en las concepciones que se gestan en el ámbito educativo, de tal modo que se ha llegado a posicionar como un término en ocasiones abstracto, resbaladizo, confuso, y saturado de adjetivos y sustantivos - un tanto maniqueistas- como arte, método- apropiado e inapropiado- ciencia, disciplina, saber, actitud, estudio, reflexión, conocimiento, teoría, enseñanza, aprendizaje, contenidos, didáctica, actividad, entre otras más, que han tejido de una u otra manera a su alrededor una telaraña de poderes discursivos y en ocasiones coercitivos de los procesos educativos.

En consecuencia, denominar como ciencia a la pedagogía es un salto a un campo con bastantes esfuerzos teóricos, pero con falta de solidez y acuerdo entre los estudiosos. Denominársele disciplina, requiere precisar el objeto de estudio, tener claridad sobre los conceptos de enseñanza/aprendizaje, correlación con métodos y modelos y tener en cuenta los procesos de contextualización o más aún encasillarla como en ocasiones ocurre con la simple teoría de la educación, es delimitar en otras palabras, su campo de acción frente las contingencias reales y cotidianas con la integralidad de los sujetos en formación permanente, donde el aprendizaje es fundamental, pues porque "Aprender es un proceso que incluye varios aspectos determinantes y se puede orientar a diversos objetivos[...] dependen generalmente del realce que se dé a uno u otro " (Assmann, 2002, p. 126).

Ahora bien, lograr una aprehensión de los elementos planteados hasta el momento, implica amparar la epistemología, que para Nidia Chaparro, Armando Duque, \& Miguel Villarraga (2000) autores del artículo titulado Sentido y alcance de la reflexión histórica y epistemológica sobre la pedagogía, es " una reflexión que contribuye a la formación de una imagen de lo que es práctica científica y la ciencia como conjunto de conocimientos" (p. 9).De modo que, es función de la epistemología inscribir teóricamente al docente a los fundamentos históricos y sociales de la educación, en concordancia con los referentes de la práctica educativa.

Por lo cual, como asegura Villárraga (2000) se requiere "proporcionar formación integral, actitud reflexiva, pensamiento crítico y una concepción científica del mundo, [...] preparación teórica sobre el quehacer docente que produzca las herramientas conceptuales desde las que se pueda orientar y modificar" (p.7); de tal modo que la práctica del maestro 
se vea re-valorada y auto - regulada, es decir, lograr de manera consciente que cada docente vaya más allá de su actividad rutinaria y propenda por "entender el ser y el quehacer de la pedagogía" (Vargas. 2007, p.27).

Hasta este punto, es probable que varios de los elementos mencionados tengan en la actualidad una fundamentación articulada -aunque a veces extrapolarizada- que dé luces sobre si la pedagogía es una disciplina que hace parte de las ciencias de la educación o es una ciencia en construcción, lo que nuevamente abre un cerco de discusión alrededor del término ciencia donde se manifiesta, como lo esbozan el Dr. Néstor Cardoso, la Dra. Nidia Chaparro y el Dr. Edgar Erazo (2009): "la pretensión de cientificidad que tiene la pedagogía, [...] condición de disciplina humanista, le exige bases teóricas sólidas" (p. 90).

Si se tiene en cuenta por lo tanto, la apreciación pospositivista sobre tal término, indicada por los autores del texto enunciado anteriormente, es necesario hacer un énfasis por comprender la dicotomía entre las ciencias sociales y las ciencias naturales. Las primeras deben su razón de ser a la unidad hermenéutica entre el sujeto y objeto de investigación, a tal grado de analizar particularmente - desde una perspectiva cualitativa, y discursiva- los sentidos y significados que genera cada proceder humano. Mientras la segunda, demarca sus intereses basándose en la objetividad, la medición, la precisión, la cuantificación, la comprobación de hipótesis, y exactitud de los fenómenos de manera general.

Por consiguiente, la pedagogía debe ser un elemento ético, moral, académico, cultural, ideológico y social constitutivo de la labor educativa que le permita al docente desde la consolidación teórica, valorar su praxis. En esta dirección, pretender adscribirla a las ciencias de la educación es algo apresurado, más aun cuando la pedagogía se erige en el seno de la comprensión de la educación y es soporte de esta, de ahí el constante andar hacia la independencia y hacia la consolidación de disciplina autónoma (Cardoso et al 2009 , p. 88). Si bien, la pedagogía acoge aspectos de diferentes campos del conocimiento como la sociología, la psicología, la historia, entre otros, la enseñanza y el aprendizaje son las matrices que dirigen su ser y quehacer en el sector educativo.

De este modo, las representaciones sociales, que se tiene frente a la pedagogía se van transformando, pues estas son:

Una forma de conocimiento específico, el saber de sentido común, cuyos contenidos manifiestan la operación de procesos generativos y funcionales socialmente caracterizados, en sentido más amplio, designa una forma de pensamiento social[...].es decir, constituyen modalidades de pensamiento práctico orientados hacia la comunicación, la comprensión y el dominio del entorno social, material e ideal (Jodelet, 1984, p. 474)

Aun así, los actuales retos de los docentes, en términos de competitividad, en muchas ocasiones hacen que estos supriman de su bagaje cognitivo los conceptos constitutivos del ámbito educativo, que deben llegar a ser una prioridad al igual que los saberes de un área específica. Acudir entonces a la epistemología, en aras de resignificar y aprehender la pedagogía, es una labor imperiosa por la que deben procurar los investigadores, buscando de manera insaciable su vinculación con las estrategias y procedimientos de constitución de aquellos conceptos científicos que erigen el campo educativo, de tal forma que se llegue a la exploración autopoiética del quehacer pedagógico. 
En este orden de ideas, se ha podido observar que al hacer referencia al término pedagogía, se hallan unos marcados lindes con lo científico, y es tal vez, dicho aspecto del que se han apegado los estudiosos del tema para elaborar un discurso con visos objetivos expresados bajo un lenguaje, en variadas ocasiones cifrado no obstante hay que resaltar que esa búsqueda y/o interés por intentar manifestarse bajo un mismo lenguaje, quiere aludir, a los elementos de corte científico que al introducirse a un medio susceptible de constantes cambios, no intentan imponer parámetros lingüísticos o normatividades escolares, sino estructurar razonamientos profundos que faciliten el diálogo e interacción entre los miembros de las comunidades académicas y científicas.

Uno de los caminos que puede conducir a la construcción sólida de los términos pertenecientes a la educación, es la actitud y formación científica para todos los docentes, con el fin que este llegue a ser un investigador o como lo denomina el Estadounidense Henry Giroux (1990), un intelectual transformativo y "en el sentido más amplio, los profesores como intelectuales han de contemplarse en función de los intereses ideológicos y políticos que estructuran la naturaleza del discurso, las relaciones sociales del aula y los valores mismos que ellos legitiman en su enseñanza" (p. 176). Todo esto, es garante de procesos epistemológicos de reflexión teórico-práctica donde se reconozcan y debatan postulados cruciales de la educación.

\section{CONCLUSIONES}

En razón a lo anterior, definir el término pedagogía a partir de una limitación exacta dentro de uno u otro universo conceptual es un gran desafío, pues esta mantiene una estrecha relación con un sin número de elementos de corte científico y pragmático, de este modo se debe promulgar es por un ejercicio reflexivo, propositivo, dialogante y holístico con todas y cada una de las problemáticas que atañen los procesos en el aula, pues es allí donde se hacen tangibles las necesidades desarrollar y el fortalecer distintas maneras de pensar, donde No se dé prioridad a un solo tipo de saber, a una sola manera de llegar a los educandos, puesto que los procesos de reflexión, construcción, evocación, diseño, contemplación y categorización se efectúan de manera multidimensional, por esto es fructífero emprender un encuentro con el saber y con la vida misma desde la experimentación y la búsqueda de miradas abiertas, factibles de cambios, donde se dé una implicación entre lo abstracto y lo práctico, donde la pedagogía sea pensada desde el interior, desde su naturaleza entramada con el ser, el convivir, el hacer y el conocer.

En síntesis, los esmeros en este escrito por tratar preocupaciones en el ámbito educativo permiten llegar a dos posibles conclusiones. La primera es que al intentar comprender la naturaleza específica de la pedagogía a través de una delimitación terminológica se hallan de modo coexistente los aspectos de índole pragmático y teórico sujetos a constantes re contextualizaciones, y la segunda, que dentro del concepto que rodea a la pedagogía y a 
la misión de la educación, debe de sobresalir el imperativo de formación docente y escolar hacia una discusión verdaderamente académica.

\section{REFERENCIAS BIBLIOGRÁFICAS}

Assmann, H. (2002). Placer y ternura en la educación. Hacia una sociedad aprendiente. Madrid: Narcea Ediciones.

Cardoso, N., Chaparro, N. y Erazo, E. (2009). Sentidos de una aproximación epistemológica a la pedagogía. Pedagogía, didáctica y concepciones de ciencia: una visión integradora. Ibagué: Universidad del Tolima.

Chaparro, N., Duque, A., y Villarraga, M. (2000). Sentido y alcance de la reflexión histórica y epistemológica sobre la pedagogía. Revista perspectiva Educativa. Vol. 2. Universidad del Tolima, Ibagué, Colombia.

Giroux, G. (1990) Los profesores como intelectuales: Hacia una pedagogía crítica del aprendizaje. Barcelona: Paidós.

Jodelet, D. (1984). La representación social: fenómenos, concepto y teoría. En S. Moscovici. Psicología Social II, pensamiento y vida social, Psicología social y problemas sociales. Barcelona: Paidós .

Vargas, G. (2007). Formación y subjetividad. Epistemología, lenguaje y pedagogía. Revista Educación y Pedagogía, 8 y 9, p. 27. Recuperado el 1 de julio de 2011 de http:// revinut.udea.edu.co/index.php/revistaeyp/article/viewFile/5674/5094 